\title{
Cortical Oscillatory Mechanisms Supporting the Control of Human Social-Emotional Actions
}

\author{
Bob Bramson, ${ }^{1}$-Ole Jensen, ${ }^{2}$-Ivan Toni, ${ }^{1 *}$ and $\odot$ Karin Roelof $\mathrm{s}^{1,3 *}$ \\ ${ }^{1}$ Donders Institute for Brain, Cognition and Behaviour, Centre for Cognitive Neuroimaging, Radboud University Nijmegen, 6525 EN Nijmegen, The \\ Netherlands, ${ }^{2}$ School of Psychology, University of Birmingham, B15 2TT Birmingham, United Kingdom, and ${ }^{3}$ Behavioural Science Institute, Radboud \\ University Nijmegen, 6525 HR Nijmegen, The Netherlands
}

The human anterior prefrontal cortex (aPFC) is involved in regulating social- emotional behavior, presumably by modulating effective connectivity with downstream parietal, limbic, and motor cortices. Regulating that connectivity might rely on theta-band oscillations (4-8 $\mathrm{Hz})$, a brain rhythm known to create overlapping periods of excitability between distant regions by temporally releasing neurons from inhibition. Here, we used MEG to understand how aPFC theta-band oscillations implement control over prepotent social-emotional behaviors; that is, the control over automatically elicited approach and avoidance actions. Forty human male participants performed a social approach-avoidance task in which they approached or avoided visually displayed emotional faces (happy or angry) by pulling or pushing a joystick. Approaching angry and avoiding happy faces (incongruent condition) requires rapid application of cognitive control to override prepotent habitual action tendencies to approach appetitive and to avoid aversive situations. In the time window before response delivery, trial-by-trial variations in aPFC theta-band power $(6 \mathrm{~Hz})$ predicted reaction time increases during emotional control and were inversely related to beta-band power (14-22 $\mathrm{Hz})$ over parietofrontal cortex. In sensorimotor areas contralateral to the moving hand, premovement gamma-band rhythms $(60-90 \mathrm{~Hz})$ were stronger during incongruent than congruent trials, with power increases phase locked to peaks of the aPFC theta-band oscillations. These findings define a mechanistic relation between cortical areas involved in implementing rapid control over human social-emotional behavior. The aPFC may bias neural processing toward rule-driven actions and away from automatic emotional tendencies by coordinating tonic disinhibition and phasic enhancement of parietofrontal circuits involved in action selection.

Key words: approach-avoidance; frontal pole; MEG; phase-amplitude coupling; social-emotional control; theta-band oscillations

\section{Significance Statement}

Being able to control social-emotional behavior is crucial for successful participation in society, as is illustrated by the severe social and occupational difficulties experienced by people suffering from social motivational disorders such as social anxiety. In this study, we show that theta-band oscillations in the anterior prefrontal cortex (aPFC), which are thought to provide temporal organization for neural firing during communication between distant brain areas, facilitate this control by linking aPFC to parietofrontal beta-band and sensorimotor gamma-band oscillations involved in action selection. These results contribute to a mechanistic understanding of cognitive control over automatic social-emotional action and point to frontal theta-band oscillations as a possible target of rhythmic neurostimulation techniques during treatment for social anxiety.

\section{Introduction}

Human cooperative social environment relies on our ability to control social-emotional behavior (Hare, 2017). The importance of this ability is illustrated by conditions in which this con-

\footnotetext{
Received Nov. 27, 2017; revised April 17, 2018; accepted May 11, 2018.

Author contributions: B.B., O.J., I.T., and K.R. designed research; B.B. performed research; B.B., O.J., I.T., and K.R. analyzed data; B.B., O.J., I.T., and K.R. wrote the paper.

K.R. was supported by a starting grant from the European Research Council (ERC_StG2012_313749) also funding B.B., and by a VICI grant (\#453-12-001) from the Netherlands Organization for Scientific Research (NW0). 0.J. was supported by James S. McDonnell Foundation Understanding Human Cognition: Collaborative Award [220020448].

The authors declare no competing financial interests.

*I.T. and K.R. contributed equally to this work.
}

trol fails. For instance, in social anxiety disorder, persistent avoidance of social interactions causes impairment in social and occupational functioning (Clark and Wells, 1995; Craske and Stein, 2016). Social-emotional disorders also illustrate how regulating social-emotional behavior requires more than suppressing automatic emotional action tendencies. In fact, social-emotional regulation is an action selection feat involving the selection of ade-

Correspondence should be addressed to Bob Bramson, Donders Centre for Cognitive Neuroimaging, Radboud University Nijmegen, Trigon Building, Kapittelweg 29, 6525 EN Nijmegen, The Netherlands. E-mail: b.bramson@donders.ru.nl.

DOI:10.1523/JNEUROSCI.3382-17.2018

Copyright $\odot 2018$ the authors $\quad 0270-6474 / 18 / 385739-11 \$ 15.00 / 0$ 
quate behaviors from numerous potential strategies while anticipating the consequences of those behaviors in other agents. For example, in a job interview, applicants might make it more likely to get the job when they overcome their tendency to avoid the test and dare to approach when asked who will present first. These emotionally laden counterfactual computations are thought to be implemented by the anterior prefrontal cortex (aPFC) (Daw et al., 2006; Boorman et al., 2009; Volman et al., 2013), a region also known to influence downstream neural activity in the amygdala and posterior parietal cortex (PPC) during emotional action control (Mars et al., 2011; Volman et al., 2011a, 2013, 2016). However, the neural mechanisms that support social-emotional regulation across this network remain unclear. In this study, we use neural oscillations as a metric for understanding how aPFC rapidly selects and implements alternative courses of action over prepotent habitual social-emotional behaviors.

Recent studies have shown that implementation of prefrontal control is often rhythmic, transferring information between regions through entrainment of neural oscillations (Helfrich and Knight, 2016). aPFC neurons tend to phase lock their spiking and gamma-band firing to the theta-band rhythm $(4-8 \mathrm{~Hz}$ ) (Ardid et al., 2015; Voytek et al., 2015). Frontal theta-band oscillations have consistently been involved in control over motivational behavior (Cavanagh and Frank, 2014; Cooper et al., 2015), including control over state-induced affective behavioral biases (Cavanagh et al., 2013) and feedback-related control in exploration behavior (Cavanagh et al., 2012). Theta-band oscillations might support emotional control by temporally orchestrating release of neurons from inhibition, thus creating overlapping periods of excitability across the cerebral network involved in social-emotional regulation (Colgin, 2013; Lisman and Jensen, 2013; Volman et al., 2013). Human aPFC has extensive anatomical connections with portions of the PPC (Mars et al., 2011; Neubert et al., 2014) and aPFC-PPC effective connectivity relies on theta-band rhythm modulations (Phillips et al., 2014; Karalis et al., 2016). Here, we test whether social-emotional action tendencies are controlled through theta-band oscillations. We explore the dynamics of interactions between theta-band oscillations in aPFC and the beta/gamma rhythms produced by posterior areas during action selection.

We measured neural activity in 40 human participants using MEG while they performed a social approach-avoidance (AA) task. In this task, participants approach or avoid visually displayed emotional faces by pulling or pushing a joystick, respectively. Approaching angry and avoiding happy faces requires implementing rapid control to override automatic tendencies to approach appetitive and avoid aversive situations. This complex form of control operates on the interaction between the emotional valence of percepts and actions and it is modulated by social psychopathologies and socially relevant hormones (Heuer et al., 2007; Louise von Borries et al., 2012; Radke et al., 2013, 2017; Enter et al., 2016).

Previous fMRI studies have shown that, during affectincongruent trials, aPFC and PPC activity is increased and amygdala activity decreased, suggesting that the aPFC exerts control over social-emotional actions, possibly by interacting with
PPC to assist in action selection (Rowe et al., 2008; Volman et al., 2011a). Building on those fMRI and electrophysiological observations, we predicted that the emotional control evoked during incongruent trials will result in stronger theta-band power in aPFC. We also explore whether theta-band oscillations over aPFC are coupled to rhythms involved in action selection; that is, beta- and gamma-band rhythms over parietofrontal areas (de Lange et al., 2008; Jenkinson and Brown, 2011; Brinkman et al., 2014; Voytek et al., 2015).

\section{Materials and Methods}

Participants. Forty-five undergraduate students from Radboud University took part in the experiment. Five participants did not complete the experiment, with three failing to follow task instructions $(>30 \%$ error trials) and two showing substantial noise in the MEG data. Forty participants were considered for analyses (mean age: 23.5 , SD: 2.8 , range: 18-33 years). All participants signed an informed consent before the study and were compensated with monetary reward or research credits. Before inclusion, participants were screened for epilepsy and history of mental illness. All participants were males, right handed, and had normal or corrected-to-normal vision. The study was approved by the local ethical committee (CMO:2014/288).

Materials and apparatus. The task was programmed using Presentation software version 16.4 (www.neurobs.com; RRID:SCR_002521). Stimuli were presented using a PROPixx beamer with a refresh rate of 120 $\mathrm{Hz}$ and a resolution of 1920:1080. MEG was acquired using a wholebrain CTF-275 system with axial gradiometers. Data were sampled at $1200 \mathrm{~Hz}$ after a $300 \mathrm{~Hz}$ low-pass filter was applied. Four sensors (MLF62, MLC32, MLC11, and MRF66) were permanently disabled due to high noise. The helmet was set at $15^{\circ}$ and the participants were seated $80 \mathrm{~cm}$ from the screen. Head location was measured using localization coils in both ear canals and on the nasion and was monitored continuously using online head localization software (Stolk et al., 2013). In case of large deviations from the initial head position $(+5 \mathrm{~mm})$, we paused the experiment and instructed the subject to move back to the original position. During the task, participants responded using a customized Fiber Optic Joystick (fORP design) calibrated for each participant before the experiment. A displacement of $20 \%$ away from the center in the sagittal plane was taken as a response.

Participants performed an AA task that has been used in several previous studies (Volman et al., 2011a,b) and was adapted for MEG (Fig. $1 A)$. Trials started with the presentation of a white fixation cross presented in the center of a black screen for $1000 \mathrm{~ms}$. After fixation, a face was presented for $100 \mathrm{~ms}$, after which the subject had $2000 \mathrm{~ms}$ to respond by pushing the joystick away or pulling it toward themselves. Participants received written instructions on screen before each block of 12 trials, in which they were instructed to push the joystick toward or away from themselves for happy or angry faces, respectively (congruent block), or 
toward/away from themselves for angry/happy faces (incongruent block). These response rules alternated each block. The task consisted of 16 blocks, yielding 196 trials in total. Stimuli consisted of equiluminant faces that were presented at the center of the screen at a visual angle of $4.3 \times 6.4$ degrees. In contrast to cognitive control tasks involving conflict on the stimulus level, such as emotional Stroop tasks, which typically implicate the anterior cingulate cortex, conflict between emotional percepts and emotional actions such as mapped by the AA task is typically processed by higher-order brain regions such as the aPFC (Volman et al., 2011a).

High-resolution anatomical MRI images were acquired with a singleshot MPRAGE sequence (acceleration factor 2 with GRAPPA method, TR $2400 \mathrm{~ms} / \mathrm{TE} 2.13 \mathrm{~ms}$, effective voxel size $1 \times 1 \times 1 \mathrm{~mm}$, 176 sagittal slices, distance factor $50 \%$, flip angle 8 degrees, orientation $\mathrm{A} \gg \mathrm{P}, \mathrm{FoV}$ $256 \mathrm{~mm}$ ). To align structural MRI to MEG, we provided the participants with vitamin E capsules in the ears on the same locations as the localizer coils in the MEG system.

Procedure. Upon arrival, participants received verbal task instructions before changing into nonmagnetic clothing. Before the experiment, participants provided a saliva sample, enabling the quantification of hormone levels for other research purposes. Once in the scanner, participants performed a practice session containing four blocks of eight trials each using faces of different identity from those displayed in the main experiment. After the main session of the AA task, participants provided a second saliva sample and completed the State Trait Anxiety Inventory (Spielberger et al., 1970). Structural MRI was acquired in a separate session in which participants also performed the AA task using fMRI. fMRI and hormonal data are not reported here.

Behavioral analysis. Reaction time analyses were performed on correct responses only. We removed trials in which the reaction time exceeded a threshold of 3 SDs above or below the mean reaction time of the subject for each condition separately ( $1.6 \%$ of trials). Congruency effects in reaction times and error rates were computed by subtracting congruent from incongruent trials.

MEG preprocessing. MEG analyses were performed using MATLAB2015a (The MathWorks; RRID:SCR_001622), Fieldtrip toolbox (Oostenveld et al., 2011), and custom-written analysis scripts. After epoching the data into trials ranging from $-3 \mathrm{~s}$ before until $1 \mathrm{~s}$ after response, we removed the third order gradient. The trials were detrended and demeaned to remove slow drifts and nonzero DC offset and filtered using a discrete Fourier transform filter to remove the $50 \mathrm{~Hz}$ line noise and 100 and $150 \mathrm{~Hz}$ harmonics. Next, we performed manual trial rejection to remove trials with large deviations or artifacts. Independent component analysis (Makeig et al., 1996) was performed to remove components that contained sources of noise (e.g., heartbeat, eye blink, joystick artifacts). After this step, all trials were inspected visually to remove any trial still containing large amounts of noise. For the sensor-level analysis, we interpolated sensors that were missing due to noise removal using a weighted average of neighboring sensors; for some sensors $(n=$ 8 ), this was not possible due to removal of too many neighbors. Sensorlevel analyses were performed on 263 sensors.

Spectral analysis. To facilitate interpretation of the topographical distribution of signal resulting from the CTF axial gradiometers, we calculated spectral power for the horizontal and vertical components of the estimated planar gradient on each sensor location, which we then summed (Bastiaansen and Knösche, 2000). This representation of the data ensures that power of a source is strongest just above that source (Hämäläinen et al., 1993).

Time-frequency representations (TFR) of power were estimated in two steps. For frequencies $<40 \mathrm{~Hz}$, we used short-time Fourier transform with sliding windows of $500 \mathrm{~ms}$, multiplied with a Hanning taper and moving in steps of $50 \mathrm{~ms}$. The frequency resolution was $2 \mathrm{~Hz}$. We prespecified $6 \mathrm{~Hz}$ as theta-band and $14-22 \mathrm{~Hz}$ as beta-band activity. Theta-band definition was based on a priori expectations (Phillips et al., 2014; Cavanagh and Frank, 2014; Cooper et al., 2015; Karalis et al., 2016). Beta-band definition was based on the congruency effect observed over all sensors. For frequencies $>40 \mathrm{~Hz}$ (gamma-band, $40-130 \mathrm{~Hz}$ ), we used three orthogonal Slepian tapers and sliding time windows of $200 \mathrm{~ms}$ (moving in steps of $50 \mathrm{~ms}$ ), creating frequency smoothing of $\sim 10 \mathrm{~Hz}$ (frequency resolution of $10 \mathrm{~Hz}$; Percival and Walden, 1993). In the gamma-band analyses, we identified changes in power evoked before response ( -1000 until $0 \mathrm{~ms}$ ) compared with a baseline period occurring before stimulus presentation (average of -800 until $-500 \mathrm{~ms}$ ). This procedure increased statistical power by narrowing the frequency search space. The frequency band showing increased power $(60-90 \mathrm{~Hz})$ was used in further (orthogonal) comparisons between conditions. With the exception of single-trial analyses, all analyses were focused on the contrast between incongruent and congruent conditions.

Source analyses. Congruency effects were localized using DICS beamforming (Gross et al., 2001). We computed a single-shell head model (Nolte, 2003) for each subject using anatomical MRI. Next, we warped the individual MRI images to a template grid in MNI space (spatial resolution of $8 \mathrm{~mm}$ ). To reconstruct activity in the interval $0.5 \mathrm{~s}$ before response delivery (period of action selection, see Results), we used a Hanning taper followed by a Fourier transform centered at $6 \mathrm{~Hz}$ and three orthogonal Slepian tapers for beta-band (center frequency $18 \mathrm{~Hz}$ ) and gamma-band (center frequency $75 \mathrm{~Hz}$ ). Slepian tapers result in more smoothing in the frequency domain and allowed us to reconstruct activity in a wider frequency range. A common spatial filter was created for each frequency based on all trials. This filter was consequently applied to congruent and incongruent trials separately. We computed relative change in power for incongruent versus congruent (incongruent - congruent)/(incongruent + congruent) to assess differences between conditions. Region labeling was done based on the Harvard-Oxford atlas implemented in FSL (https://fsl.fmrib.ox.ac.uk/fsl/fslwiki/; RRID: SCR_002823).

Spatial filters applied to ROIs. To assess whether gamma-band power is linked to theta-band phase, we constructed three spatial filters using linearly constrained minimum variance beamforming. Peak locations for the phase amplitude analyses were defined based on the peak grid-point resulting from the group level brain-behavior correlation analysis for the theta-band (aPFC; MNI: 4048 -6) and the group-level gamma-band congruency effect [left postcentral gyrus $(-28-3264)$ and right parietal superior lobule/postcentral gyrus $(28-4270)]$. These filters were applied to the MEG data, after which the dipole direction containing most variance was extracted.

Brain-behavior correlations. The source-reconstructed neural congruency effects in theta- and beta-band power were correlated with condition differences in reaction time (behavioral congruency effect). We calculated the correlation between the behavioral and the neural congruency effects for each grid point, after which we used Fisher's $z$ transform to convert Spearman's $r$ values into $z$ values.

Trial-by-trial estimates $(-0.5 \mathrm{~s}$ until response) of aPFC theta-band power were obtained from aPFC peak grid point resulting from the group brain-behavior correlation (centered at $4048-6$ ). Trial-by-trial estimates of parietofrontal beta-band power were obtained from a precentral grid point (centered at $50-1036$ ) resulting from the group-level brain-behavior correlation. For each subject, we set up a multiple regression model. First, we used trial-by-trial estimates of theta-band power (aPFC), beta-band power (precentral), and their interaction $\left(\right.$ theta $_{\mathrm{aPFC}}{ }^{\star}$ beta $\left._{\text {precentral }}\right)$ as predictors of the time series of reaction times separately for congruent and incongruent trials. The regressors were $z$-scored within each condition and regression parameters were estimated for each condition and participant separately using robust regression (MATLAB function robustfit). Standardized beta values for each subject were used in a second-level analysis testing whether trial-by-trial aPFC theta-power and precentral beta-power better accounted for reaction time variance during incongruent than during congruent trials (one-sided dependent-sample $t$ tests in SPSS; RRID:SCR_002865) and whether those regression effects were different from zero (one-sample $t$ tests). In this approach, single-trial estimates of power are regressed against single-trial reaction times separately for each condition, a procedure that is orthogonal to the group-level correlation between behavioral congruency and congruency in theta- and beta-band power.

Connectivity analysis. To assess whether aPFC influences downstream areas by influencing beta-band activity, we correlated condition differ- 
ences in theta-band power extracted from aPFC (MNI: 4048 -6) with whole-brain condition differences in beta-band power. Spearman's $r$ values were transformed to $z$ values using Fisher's transform.

For theta-gamma coupling, we decomposed a spatial filter applied to the aPFC (MNI: $4048-6$ ) into $6 \mathrm{~Hz}$ complex signal using STFFT with a $500 \mathrm{~ms}$ window tapered with a Hanning filter, moving in steps of $1 \mathrm{~ms}$, after which the peak times between $-0.5 \mathrm{~s}$ and response were extracted. Next, we time locked the remaining reconstructed time series (which were extracted from peak locations in the gamma-band condition difference) around each theta-band peak time point. From this (theta peaklocked) signal, we extracted gamma-band $(40-130 \mathrm{~Hz})$ power by performing STFFT tapered with a Hanning window containing six cycles per frequency band ( $\mathrm{dT}=6 / \mathrm{f})$ and moving in steps of $10 \mathrm{~ms}$. We computed relative change in TFR between conditions for the phase-locked gamma-band power. We tested whether the gamma-band condition difference changed as a function of the phase of the theta-band extracted from aPFC, an approach that is orthogonal to testing for a difference between the experimental conditions. For interpretational purposes, we also computed the event-related field of the phase-locked signal from the aPFC to show the underlying theta-band waveform shape.

Statistical analyses. Statistical analyses on the sensor and source level consisted of cluster-based nonparametric permutation tests (Maris and Oostenveld, 2007). This procedure ensures correction for multiple comparisons over time of sensors (or grid points) and frequencies while also taking into account the dependency in the data by clustering neighboring points showing the same effect. As test statistics, we used $t$-values on the sensor-level data, $z$-values (fisher transformed $r$ values) for brain-behavior correlations and theta-beta connectivity, and relative change (incongruent - congruent)/(congruent + incongruent) for the theta-gamma coupling. Unless stated otherwise, the reported $p$-values refer to cluster-corrected statistics.

\section{Results}

Behavioral costs of control over social-emotional action

Reaction times were longer for incongruent $(\mathrm{M}=722 \mathrm{~ms}, \mathrm{SD}=$ 176) compared with congruent trials $[\mathrm{M}=680 \mathrm{~ms}, \mathrm{SD}=147$; $t_{(39)}=-4.33, p<0.001$; Fig. $1 B$; effect size $d=0.26$, calculated as (M1 - M2)/SD $\left.\mathrm{S}_{\text {pooled }}\right]$. In addition, we found higher accuracy levels for affect-congruent $(\mathrm{M}=95.4 \%, \mathrm{SD}=4)$ versus incongruent trials $(\mathrm{M}=92.3 \%, \mathrm{SD}=6.5)\left(t_{(39)}=3.07, p=0.004, d=\right.$ $0.57)$. These results illustrate that the task is effective in inducing behavioral costs when participants need to override their emotional action tendencies.

\section{aPFC theta-band power increases during emotional action control}

As detailed in the introduction, we hypothesized that frontal theta-band activity would be involved in control over socialemotional action tendencies. We found stronger theta-band power over anterior sensors before response during control of automatic emotional actions (i.e., incongruent vs congruent trials; center-frequency: $6 \mathrm{~Hz}$, Fig. $2 A, B$ ). This congruency effect is statistically significant between 350 and 100 ms (maximum difference at $200 \mathrm{~ms}$ ) before response initiation when controlling for multiple comparisons over sensors $(N=66$; ROI on all anterior channels) and time points $(p=0.016$; Fig. $2 A, C)$. Reconstructing the source locations of this difference showed increases of theta-band activity for incongruent trials with local maxima at right frontal pole (aPFC)/superior frontal gyrus (20 40 50), frontal pole (2670 8), and frontal orbital cortex (12 24-24) (Fig. 2D), with the strongest theta-band increases in the before response ( 20 40 50; Fig. 2E).

To localize theta-band activity that is relevant for behavior, we correlated condition differences in theta-band power $-0.5 \mathrm{~s}$ before until response in each grid point with reaction time effects over participants. ROI analysis on all frontal areas yielded a clus- ter of activity where the theta-band congruency-effect correlated positively with reaction time congruency effect (Fig. $2 F, G, r_{(38)}=$ $0.52, p=0.0007$ at peak grid point and $r_{(38)}=0.44, p=0.045$ for the whole cluster, corrected for multiple comparisons over grid points). This cluster had two local maxima at MNI coordinates 40 $48-6$ and 2830 40, which correspond to right frontal pole and middle frontal gyrus/superior frontal gyrus, respectively. This result indicates that those participants that show greater affect incongruency (as indexed by increased reaction times for incongruent vs congruent trials) also engage aPFC more strongly. Contralateral (left) frontal pole/inferior frontal gyrus showed similar correlations (maximum at -343612 ), but this cluster remained below the cluster correction threshold. No clusters survived whole-brain thresholding.

Next, we implemented a post hoc exploratory analysis to determine whether the relation between increased theta-band power and emotional action control holds even on a trial-by-trial basis. Comparing single trial theta-band power derived from aPFC (MNI: $4048-6$ ) using one-sided $t$ tests confirmed significant differences between conditions for theta-band power $\left(t_{(39)}=\right.$ $-1.77, p=0.043)$. Theta-band power in the incongruent condition significantly correlated with behavioral performance in the same condition $\left(t_{(39)}=2.69, p=0.005\right)$. This was not the case for the congruent condition $\left(t_{(39)}=-0.29, p=0.77\right)$. Together, these results confirm our hypothesis that theta-band power is a positive predictor of reaction time and show that aPFC is recruited more strongly with increased incongruence on a subject-by-subject as well as on a trial-by-trial basis.

\section{Parietal and frontal beta-band activity decreases during emotional action control}

Next, we tested whether an increase in theta-band power would be accompanied by parietal beta-band desynchronization. A large cluster of decreased alpha-/beta-band power in the incongruent versus the congruent condition resulted from the wholebrain sensor-level analysis (Fig. $3 A, B$ ), with significant condition differences between $600 \mathrm{~ms}$ before response until response onset (maximum difference at time $0, p=0.0064$; Fig. $3 C$, corrected for multiple comparisons over time points; sensors, $N=263$ ) and frequencies. Differences were present over most sensors (Fig. $3 B$ ) and ranged from $8-26 \mathrm{~Hz}$ (Fig. $3 A$ ), with a peak between 12 and $18 \mathrm{~Hz}$. Splitting the observed effect in alpha-band $(8-12 \mathrm{~Hz})$ and beta-band (14-26 Hz) (de Lange et al. (2008)) showed a significant decrease for beta-band activity $(14-26 \mathrm{~Hz}, p=0.0023$; -600 until response), but not for alpha-band $(8-12 \mathrm{~Hz}, p=$ 0.11 ). For source reconstruction of the beta-band activity, we used $18 \mathrm{~Hz}$ as center frequency with a frequency smoothing of 4 $\mathrm{Hz}$ (giving 14-22 Hz) (de Lange et al., 2008; Jenkinson and Brown, 2011; Brinkman et al., 2014). Reconstructing beta-band activity revealed condition differences (i.e., stronger beta-band desynchronization in the incongruent condition) with a maximum in the right superior parietal lobule/supramarginal gyrus $(44-40$ 56; Fig. 3D). Time series reconstruction from right superior parietal lobule (Fig. $3 E$ ) illustrates that the beta-band desynchronization in this area peaks just before response and suggests a tight temporal relation with the frontal theta-band effect. These results, combined with the aforementioned thetaband results, indicate the involvement of aPFC theta-band and PPC beta-band activity during the control over social-emotional action tendencies, in close anatomical correspondence with previous studies on the control over emotional behavior (Volman et al., 2011a, 2013). 
A

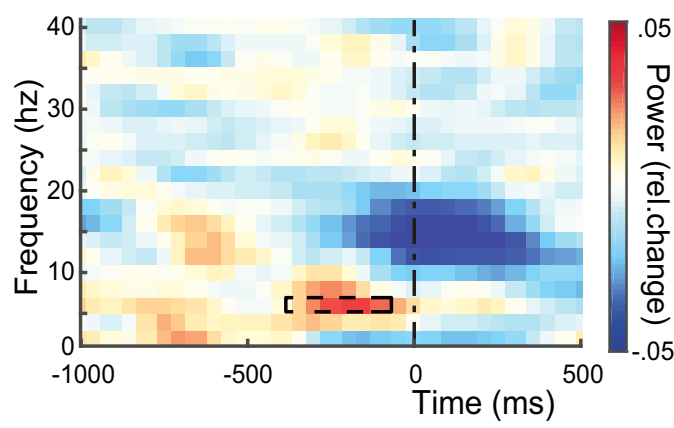

B

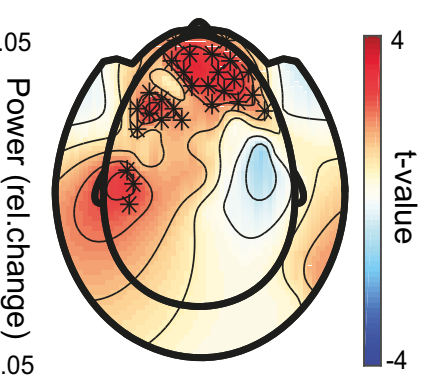

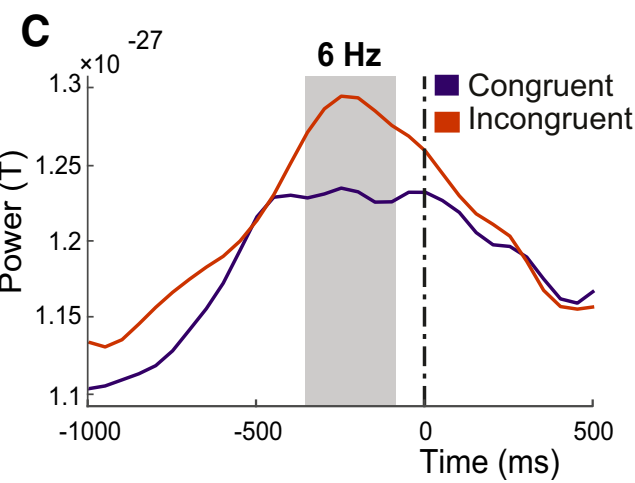

D

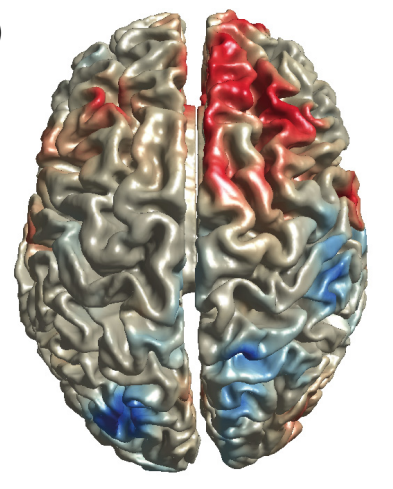

$\mathbf{F}$

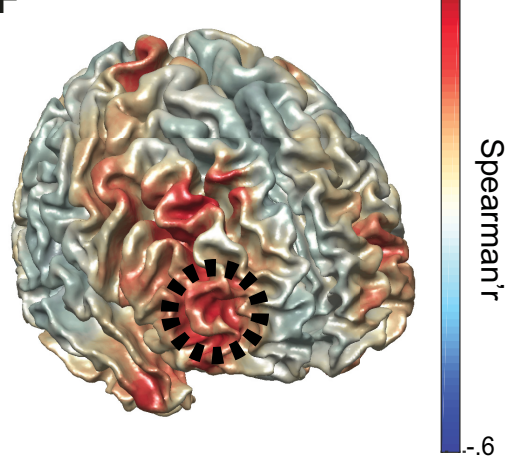

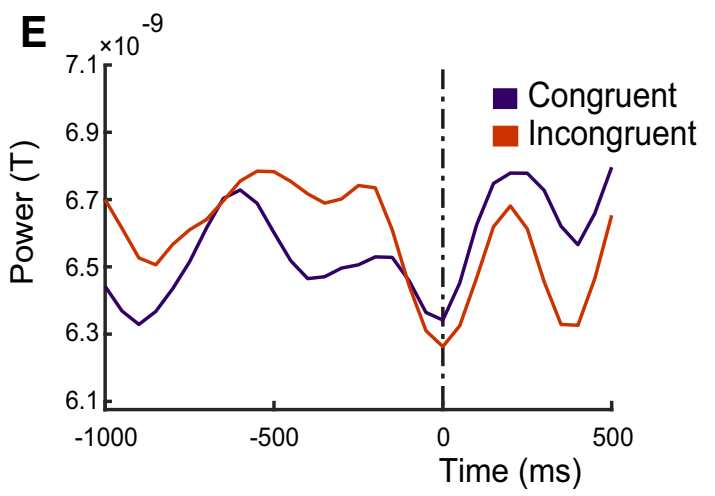

G

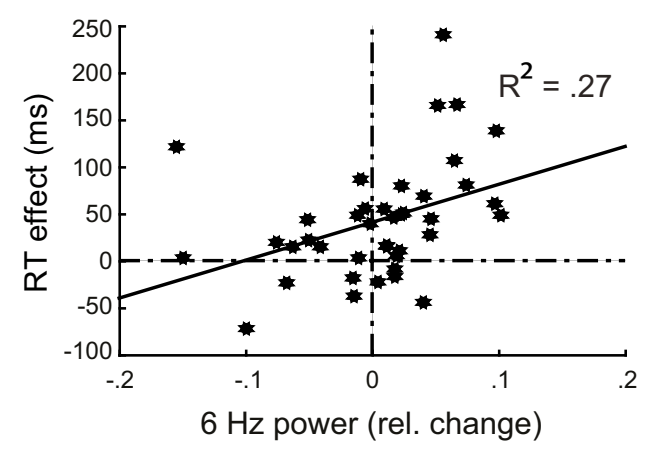

Figure 2. Emotional control increases theta-band power in aPFC. $A$, Time-frequency plot of between conditions power differences (congruency effect: incongruent - congruent/congruent + incongruent) averaged over sensors with a significant effect (see $\boldsymbol{B})$. Time 0 : response onset. The dashed box shows the time-frequency interval with a significant congruency effect $(-350$ to -100 ms before response; $6 \mathrm{~Hz}$ ). $\boldsymbol{B}$, Topographic distribution of sensors with a significant congruency effect at $6 \mathrm{~Hz}$ (stars). $\boldsymbol{C}$, Changes over time in theta-band power (6 Hz) averaged across significant sensors (see $\boldsymbol{B}$ ). The epoch with a significant difference between conditions is marked in gray. $\boldsymbol{D}$, Cortical distribution of theta-band congruency effects. $\boldsymbol{E}$, Time series of $6 \mathrm{~Hz}$ activity extracted from right frontal pole/superior frontal gyrus (20 40 50).F, Cortical distribution of correlations between theta-band and behavioral congruency effects, with a significant cluster over aPFC (dashed black circle, MNI coordinates of local maximum: 4048 -6). G, Correlation between theta-band and behavioral congruency effects. Black dots represent measurements from each participant. Theta-band power changes are extracted from the local maximum in aPFC.

Correlating beta-band power and behavioral congruency differences revealed a large cluster $\left(r_{(38)}=-0.68, p<0.0001\right.$ peak grid point and $r_{(38)}=-0.48, p<0.0001$ whole cluster) over right precentral/postcentral gyrus with local maximum at $48-236$ (Fig. $3 F$ ). This correlation indicates that participants with a large behavioral congruency effect show larger suppression in betaband power (Fig. 3G). Single trial beta-band power extracted from the peak location $(48-236)$ was significantly correlated with behavioral performance $\left(t_{(39)}=-3.06, p=0.002\right.$ for incongruent, but not for congruent trials; $\left.t_{(39)}=-0.137, p=0.45\right)$ and also differed significantly between conditions $\left(t_{(39)}=1.8, p=\right.$ $0.04)$. This indicates that beta-band desynchronization over parietofrontal regions is behaviorally relevant when control over social-emotional actions is implemented.
Effective connectivity between aPFC and parietofrontal areas during emotional action control

As a next step, we tested whether aPFC theta-band activity modulates rhythms involved in action selection. To assess connectivity between aPFC theta-band power and activity in anatomically downstream areas, we correlated the condition difference in aPFC theta-band power (MNI: $4048-6$, local maximum of brain-behavior congruency effects (Fig. $2 F, G$ ) with the condition difference in beta-band power across each brain grid point on a subject-by-subject basis. Whole-brain analysis yielded a significant cluster $\left(r_{(38)}=-0.61, p<0.0001\right.$ peak grid point; $r_{(38)}=$ $-0.46, p=0.021$ whole cluster; corrected for multiple comparisons over grid points) over right precentral gyrus/postcentral 
A

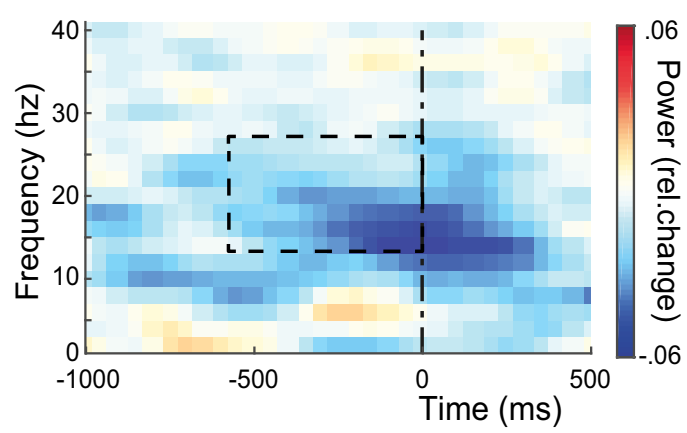

B

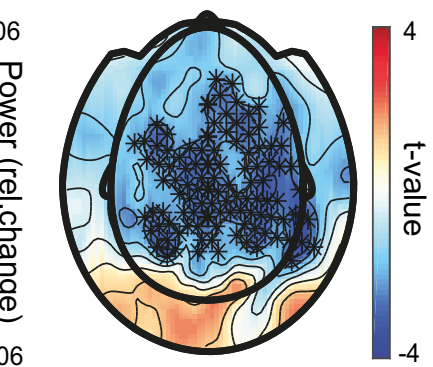

C

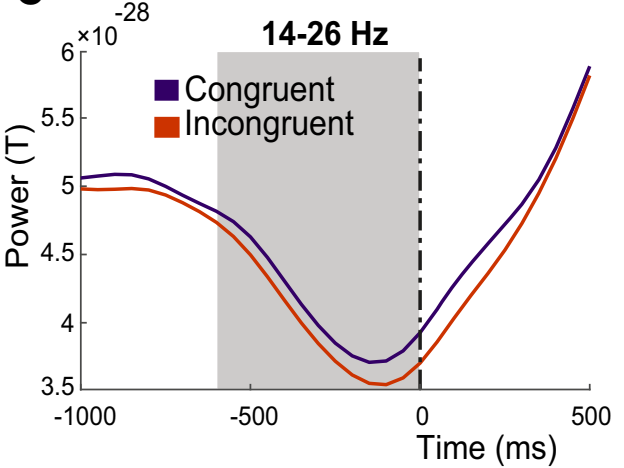

D

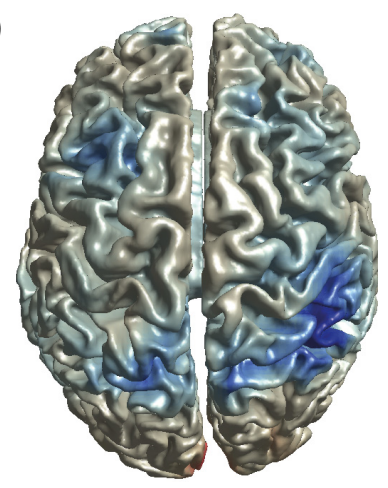

F

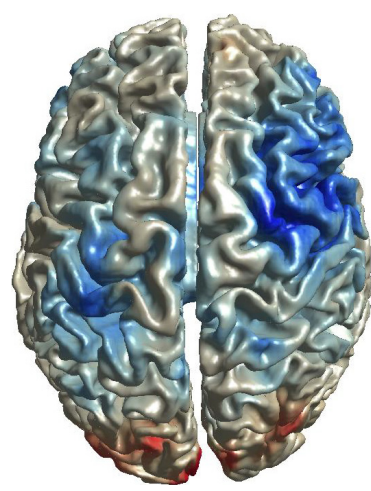

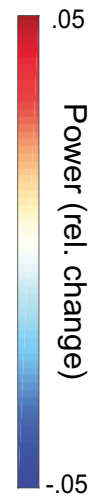

E

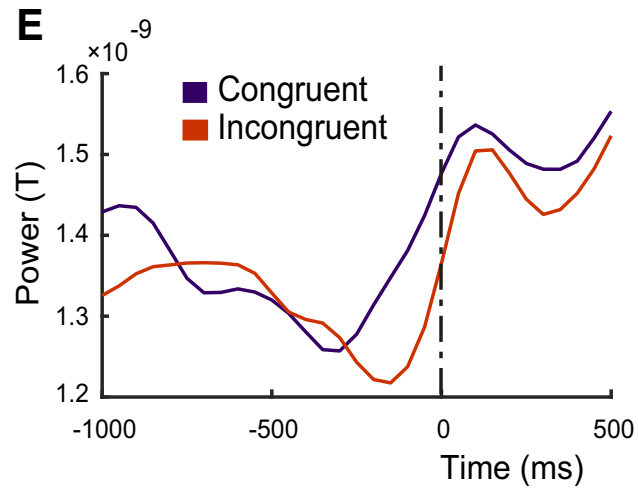

G

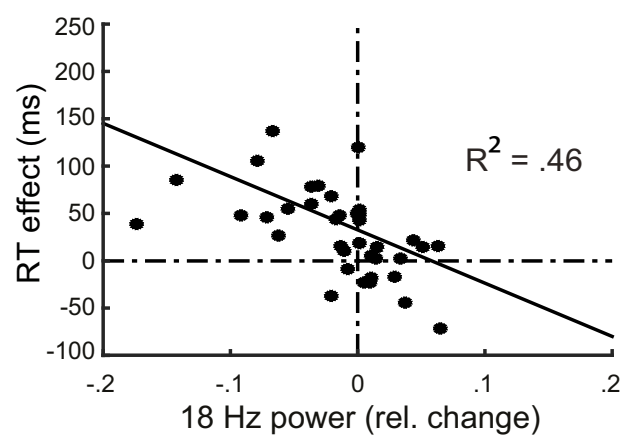

Figure 3. Emotional control decreases beta-band power in parietal and frontal cortex. $\boldsymbol{A}$, Time-frequency plot of between conditions power differences (congruency effect: incongruent congruent/congruent + incongruent) averaged over sensors with a significant effect (see $\boldsymbol{B}$ ). Time 0 : response onset. The dashed box shows the time-frequency interval with a significant congruency effect ( -600 to 0 ms before response; $14-26 \mathrm{~Hz}$ ). $\boldsymbol{B}$, Topographic distribution of sensors with a significant congruency effect at $14-26 \mathrm{~Hz}$ (stars). $\boldsymbol{C}$, changes over time in beta-band power $(14-26 \mathrm{~Hz}$ ) averaged across significant sensors (see $\boldsymbol{B})$. The epoch with a significant difference between conditions is marked in gray. $\boldsymbol{D}$, Cortical distribution of beta-band congruency effects (center frequency, $18 \mathrm{~Hz}$ ). $\boldsymbol{E}$, Time series of $18 \mathrm{~Hz}$ activity extracted from superior parietal lobule $(44-4056)$. $\boldsymbol{F}$, Cortical distribution of correlations between beta-band (18 Hz) and behavioral congruency effects, with a significant cluster over right precentral gyrus (MNI coordinates of local maximum: $48-236$ ). G, Correlation between beta-band and behavioral congruency effects. Black dots represent measurements from each participant. Beta-band power changes are extracted from the right precentral maximum.

gyrus with a local maximum at 50 - 1036 extending anteriorly into the middle frontal gyrus and posteriorly into the superior parietal lobule (Fig. 4A,B). Contralateral (left) precentral gyrus/ postcentral gyrus showed similar connectivity below the wholebrain-corrected threshold. This effect indicates that participants with larger increases in aPFC theta-band power during control over social-emotional actions also show a larger decrease in betaband power over parietofrontal areas. These findings suggest functional coupling between those two oscillatory phenomena in those two cortical regions. There were no significant connectivity effects after ROI analysis over the parietal cortex (Volman et al., 2011a), exploratory correlational analyses with the (theta-band) seed grid point at 2830 40; middle frontal gyrus/superior frontal gyrus; single-trial correlations between aPFC theta-band and beta-band activity from the connectivity peak location (50 - 10 36 ), or exploratory phase-amplitude coupling between aPFC theta-band phase and precentral beta-band power.

\section{Gamma-band activity increases during emotional action control}

Given that the aPFC theta-band is thought to provide temporal organization to gamma-band activity (Lisman and Jensen, 2013; Voytek et al., 2015), we explored whether controlling emotional action tendencies resulted in changes in gamma-band power. To determine the frequency range of gamma-band activity evoked in these experimental setttings, we first compared gamma-band power evoked before response with gamma-band power during baseline over all trials. This comparison showed an increase in 
A

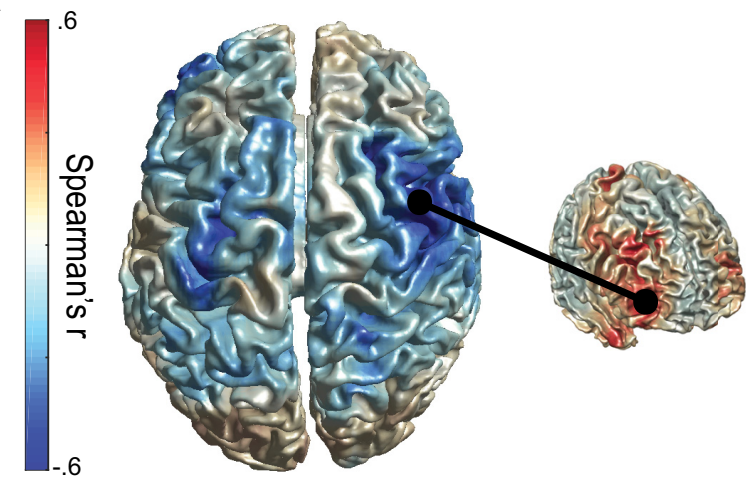

B

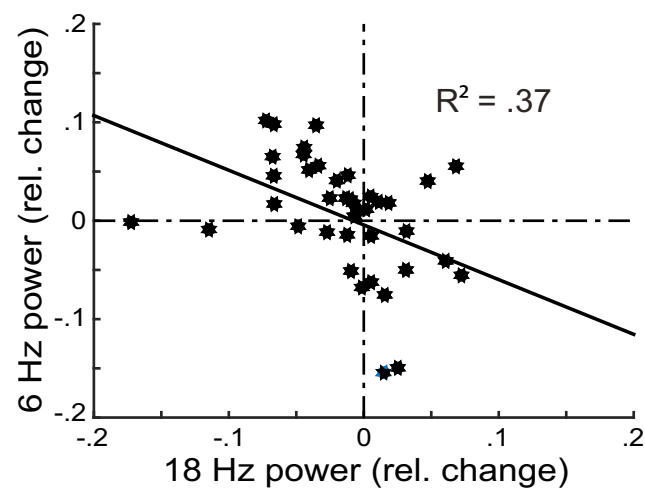

Figure 4. Emotional control increases connectivity between aPFC and frontoparietal areas. $A$, Cortical distribution (uncorrected for multiple comparisons) of correlations between beta-band congruency effects and theta-band congruency effects extracted from aPFC (in red, from Fig. 2E). The cluster over the right precentral gyrus (MNI coordinates of local maximum: $50-1036$ ) is significant. $\boldsymbol{B}$, Correlation between aPFC theta-band and precentral beta-band congruency effects. Black dots represent measurements from each participant. Beta-band power changes are extracted from the right precentral maximum.

power between 60 and $90 \mathrm{~Hz}$ (midgamma range; Buzsáki and Wang (2012)) localized over central sensors $(p=0.027$ corrected for multiple comparisons over frequencies, time points, and sensors; $N=263$ ). Comparing $60-90 \mathrm{~Hz}$ gamma-band power between conditions showed stronger power for incongruent than congruent trials over central sensors (Fig. $5 A, B$ ) starting $350 \mathrm{~ms}$ before response until $50 \mathrm{~ms}$ before response ( $p=0.03$; Fig. $5 C$ ) corrected for multiple comparisons for time points and sensors $(N=263)$. Source reconstruction of gamma-band condition differences showed power increases with local maxima in right parietal superior lobule/postcentral gyrus $(28-4072)$, left postcentral gyrus $(-28-3264)$, and left superior frontal gyrus $(-12$ 16 64) (Fig. 5D), indicating increased engagement of sensorimotor and parietal areas during control over prepotent habitual actions (Fig. 5E). There was no significant correlation between gamma-band congruency and reaction time congruency effects $\left(r_{(38)}=0.26, p=0.097\right)$.

Finally, to determne whether aPFC's control over automatic action tendencies may involve coupling to sensorimotor gammaoscillations, we explored the presence of phase-amplitude coupling between theta-band phase at aPFC $(4048-6)$ and gamma-band power over left central sulcus $(-28-3264)$ and right parietal superior lobule/postcentral gyrus $(28-4270)$. In the incongruent condition, there was stronger gamma-band power over left postcentral gyrus during peaks, but not during troughs, of the aPFC theta-band signal $(p=0.013, p=0.015$, and $p=0.025$ for the first, second, and third cluster, respectively, shown in Fig. $5 F$; left to right corrected for multiple comparisons over time points and frequencies). These results indicate that the increased gamma-band power evoked over controlateral sensorimotor cortex during the control of prepotent habitual actions might be guided by long-range communication between aPFC and those sensorimotor areas.

\section{Discussion}

This study explores neurophysiological mechanisms implementing control over social-emotional behavior. We show that the known contributions of aPFC and PPC to the control of socialemotional behavior are implemented through modulations of neural rhythmic activity in the theta-, beta-, and gamma-bands. More precisely, when participants select an affect-incongruent response to emotional faces, theta-band power increases over aPFC. The increase in theta-band power corresponds to de- creases in beta-band power over parietofrontal cortex and theta phase-locked increases in gamma-band power over sensorimotor areas. Those modulations of neural rhythmic activity, as well as their temporal dynamics, are behaviorally relevant for the control of social-emotional behavior, both between and within subjects. Trial-by-trial increases in reaction times during incongruent trials are accounted for by increases in theta-band power over aPFC and decreases in beta-band power over parietofrontal cortex.

\section{Prefrontal theta-band oscillations during control of social-emotional behavior}

Previous work has shown the importance of theta-band oscillations in overcoming motivational action biases in favor of goaldirected behavior (Cavanagh et al., 2013). These theta-band oscillations, evoked in the context of a Pavlovian learning paradigm, emerged from the medial prefrontal cortex (mPFC), a region frequently associated with cognitive control involving action inhibition (Ridderinkhof et al., 2004) and conflict monitoring (Etkin et al., 2006, 2011). Here, we add two novel elements to that knowledge. First, we show that the theta-band rhythm is also involved in the proactive control of social-emotional action tendencies requiring the rapid selection of actions alternative to a prepotent habitual response. This instance of cognitive control operates on the interaction between emotional percepts and action selection over and above the emotional value of the stimulus or the emotional value of the response alone. Second, the thetaband rhythm supporting this type of cognitive control emerges from the anterior lateral prefrontal cortex.

The increased theta-band power observed in this study could be an instance of low-frequency modulations of cortical ensembles (Jensen and Mazaheri, 2010); for example, the frequently observed theta-based coordination of mediofrontal neuronal ensembles during rule retrieval (Colgin, 2013; Harris and Gordon, 2015). However, the anatomical location and functional characteristics of the theta-band effect suggest a more specific mechanism: we show that this theta-band-related form of control emerged before response delivery from the aPFC rather than during feedback processing from medial frontal sources previously associated with inhibitory control and memory retrieval (Cavanagh et al., 2012; Colgin, 2013; Cavanagh and Frank, 2014). The aPFC, consistently shown to be involved in previous fMRI and transcranial magnetic stimulation studies of social-emotional action control (Kalisch, 2009; Volman et al., 2011a, 2013; 


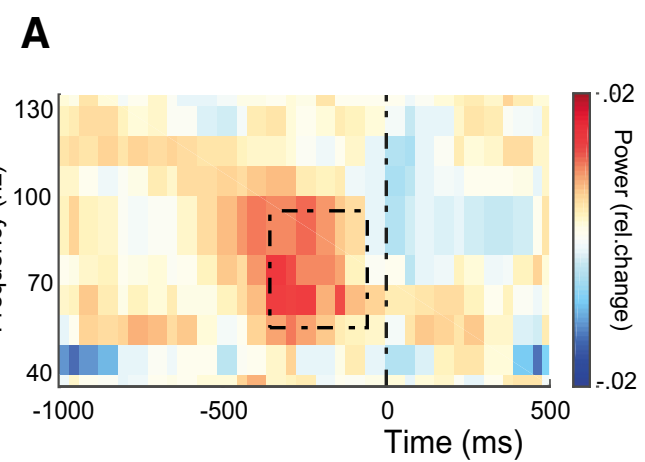

B

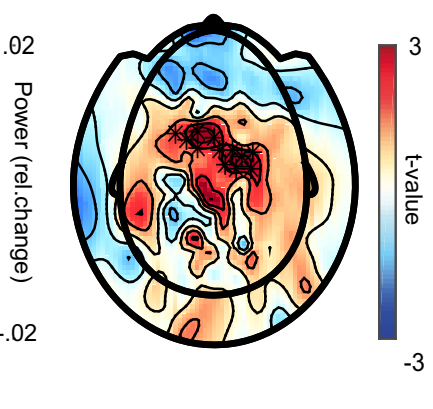

C

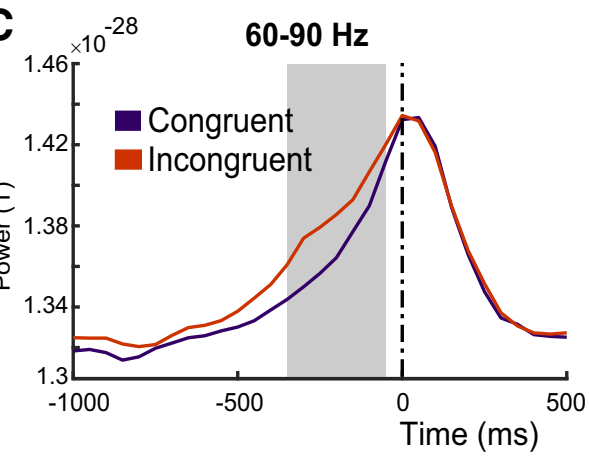

D

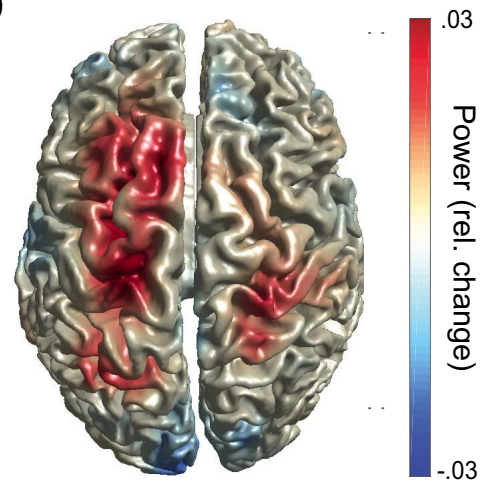

$\mathbf{F}$

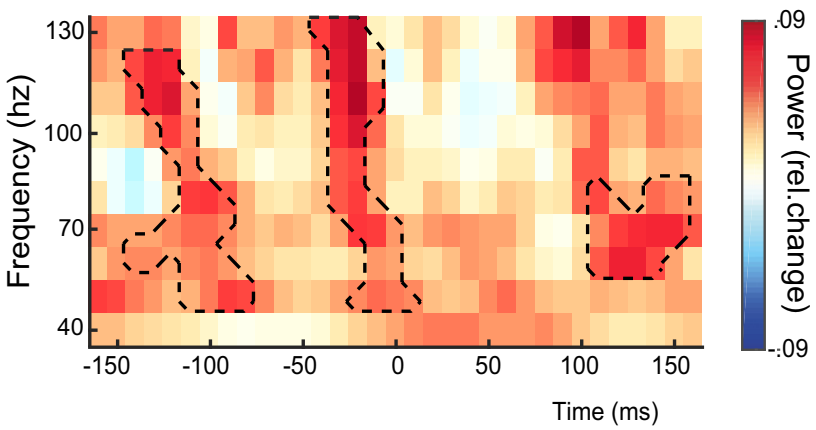

$\mathbf{E}$

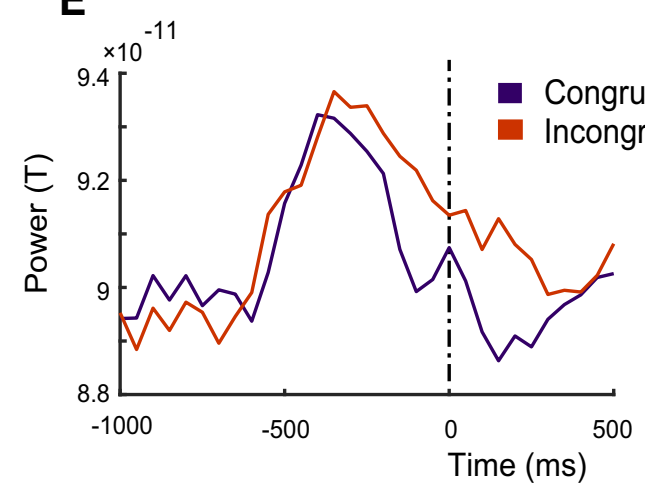

G

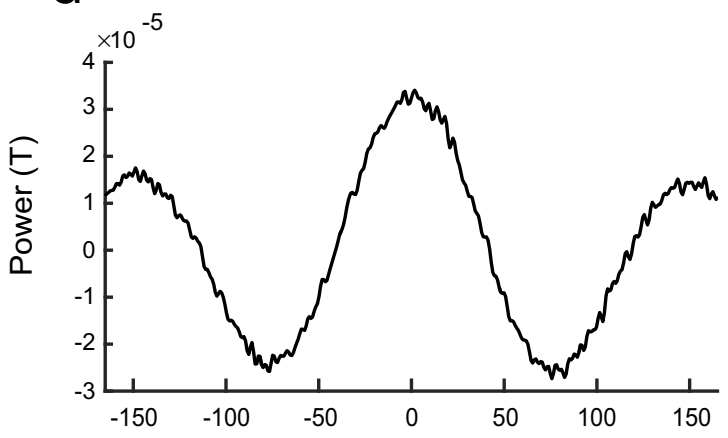

Figure 5. Emotional control increases gamma-band power in parietal and frontal cortex during peaks of theta-band oscillations in aPFC. $A$, Time-frequency plot of between conditions power differences (congruency effect: incongruent - congruent/congruent + incongruent) averaged over sensors with a significant effect (see $\boldsymbol{B}$ ). Time 0 : response onset. The dashed box shows the time-frequency interval with a significant congruency effect ( -350 to $-50 \mathrm{~ms}$ before response; $60-90 \mathrm{~Hz}$ ). $\boldsymbol{B}$, Topographic distribution of sensors with a significant congruency effect at $60-90$ $\mathrm{Hz}$ (stars). C, Changes over time in gamma-band power $(60-90 \mathrm{~Hz})$ averaged across significant sensors (see $\boldsymbol{B})$. $\boldsymbol{D}$, Cortical distribution of relative gamma-band congruency effects, with a significant cluster around the left central sulcus $(-28-3264)$. $\boldsymbol{E}$, Time series of $60-90 \mathrm{~Hz}$ activity extracted from left central sulcus $(-28-3264)$. $\boldsymbol{F}$, Time-frequency plot of gamma-band power congruency effects extracted from the local maximum in the left central sulcus $(\boldsymbol{F})$ phase-locked to the aPFC theta-band signal before response. Contours are drawn around significant clusters where power is stronger in incongruent versus congruent trials. $\mathbf{G}$, Event-related field of the theta-band signal extracted from aPFC.

Morawetz et al., 2017), has been associated with the ability to control immediate action tendencies while implementing more abstract goals (Burgess et al., 2007; Badre and D’esposito, 2009; Koechlin, 2016; Mansouri et al., 2017), possibly by keeping online nonchosen response options (Boorman et al., 2009). Controlling emotional action tendencies, unlike emotional Strooplike tasks involving stimulus-level conflict, requires considering the relative benefit of the unchosen behavioral strategy before a switch in response set is implemented (Boorman et al., 2009). The timing, anatomical location, and downstream effects of the current theta-band findings fit with the notion that control of emotional action tendencies involves maintenance of counterfactual choices in aPFC.

\section{Parietofrontal beta-band oscillations during control of social-emotional behavior}

Emotional control evoked beta-band desynchronization localized to parietal cortex. Those features are not compatible with the beta-band synchronization elicited in inferior frontal gyrus during action inhibition (Swann et al., 2012; Aron et al., 2014; Bastin et al., 2014; Picazio et al., 2014). Here, beta-band desynchronization likely reflects increased engagement of areas involved in action selection (Brinkman et al., 2014) through release from tonic cortical inhibition (Khanna and Carmena, 2017) and increased corticospinal excitability (van Elswijk et al., 2010). This release from inhibition is facilitated by decreases in GABA-ergic tone (Jensen et al., 2005; Yamawaki et al., 2008) and is accompanied by 
increased gamma-band and spiking activity (Spinks et al., 2008; Donner et al., 2009). The parietofrontal reduction in beta-band power that we observed is inversely proportional to trial-by-trial slowing of responses during incongruent trials and significantly more so than during congruent trials, suggesting that this effect is not a trivial consequence of participants preparing a generic motor response, nor a systematic effect of task difficulty. In fact, the enhanced tonic beta-band desynchronization observed during incongruent trials might reflect stronger disinhibition of parietofrontal circuits when competition between multiple possible actions needs to be resolved and a larger neuronal search space needs to be considered (Cisek and Kalaska, 2010; Grent-'t-Jong et al., 2013; Brinkman et al., 2014).

\section{Sensorimotor gamma-band oscillations during control over social-emotional behavior}

Gamma-band synchronization in the motor system is linked to action preparation and movement selection (Donner et al., 2009; Schoffelen et al., 2011). When multiple response options are available during action preparation, such as during response conflict, increases in gamma-band oscillations are observed. This is often interpreted as simultaneous activation of multiple active response sets (Gaetz et al., 2013; Grent-'t-Jong et al., 2013), with an automatically triggered action competing with an alternative rule-based action. The increase in gamma-band power that we observed in the affect-incongruent condition might reflect enhanced coordination of local neuronal ensembles (Buzsáki and Wang, 2012) toward a state space suitable to initiate the correct, rule-based action (de Lange et al., 2008; Churchland et al., 2010; Kaufman et al., 2014) and away from the prepotent habitual action state. The phasic temporal relation between increases in central gamma-band power and peaks in aPFC theta-band oscillations indicates that selection of an alternative action could be implemented through interregional communication via phase-dependent modulations of gamma-band rhythms (Lisman and Jensen, 2013; Voytek et al., 2015).

\section{Interpretational issues}

It remains to be seen whether the relation between theta-band effects in aPFC and downstream beta- and gamma-band effects constitutes a functionally directional and monosynaptic interaction. It is known that aPFC sits at the top of the prefrontal hierarchy and projects to parietal and premotor areas (Ramnani and Owen, 2004; Miller and D'Esposito, 2005; Voytek et al., 2015; Koechlin, 2016) and the timing of our effects suggests that aPFC might provide top-down regulation. However, given the lack of precise knowledge on the feedforward versus feedback connectivity of this circuit in humans (Neubert et al., 2014), the directionality of these effects remains elusive. The current findings do not exclude that other regions involved in emotional action selection could mediate interregional couplings between $\mathrm{aPFC}$ and parietofrontal cortex; for example, the pulvinar (Tyborowska et al., 2016) or the amygdala. The latter has been shown to be downregulated by aPFC during social-emotional control (Volman et al., 2013) and is influenced directly by frontal theta-band oscillations during freezing (Karalis et al., 2016).

It could be argued that the theta-band effects that we report are generic byproducts of increased anxiety during incongruent trials. Previous studies have shown that theta-band activity in $\mathrm{mPFC}$ is involved in anxiety and fear behavior (Cavanagh and Shackman, 2015; Harris and Gordon, 2015), with increased theta-band connectivity between hippocampus and mPFC dur- ing fear-related inhibition of behavior (Adhikari et al., 2010; Khemka et al., 2017) and increased theta-band activity over mPFC in anxious individuals (Cavanagh and Shackman, 2015). However, the current changes in theta-band power were modulated by variations in performance on a trial-by-trial basis, an effect orthogonal to the systematic changes possibly related to state anxiety.

Source-level changes in aPFC theta-band and frontoparietal beta-band power arise in the right hemisphere. However, inspection of the data shows subthreshold effects in the corresponding contralateral regions, suggesting that the right hemispheric lateralization is a threshold effect of a bilateral process, which is consistent with previous fMRI reports (Volman et al., 2011b, 2013) and with the sensor-level scalp topographies.

The anterior frontal location of the theta-band effect could be an artifact driven by task-related changes in head or eye position. This potential source of between-conditions differences is unlikely to account for the findings. There were identical stimuli and movements across conditions, head movements were monitored with millimeter precision during task performance (Stolk et al., 2013), and ocular artifacts were aggressively removed with independent components analysis.

Phase-amplitude couplings can be inflated by nonsinusoidal oscillations (Lozano-Soldevilla et al., 2016; Cole et al., 2017), sharp transients in the data (Aru et al., 2015) or harmonics of lower frequencies (Jensen et al., 2016). In our case, theta-related harmonics and sharp transients are unlikely to play a role given that the theta-band and gamma-band signals originated from different cortical regions, with a clear sinusoidal theta-band signal in aPFC. Stronger theta-band power during incongruent trials might lead to more robust phase estimation, but this does not invalidate the presence of increased gamma-band power during peaks of the theta-band oscillation in aPFC.

\section{Conclusion}

This study defines neural responses to the problem of controlling human social-emotional behavior. Participants implement rapid changes in their predominant response set and select an alternative course of action by increasing theta-band power over aPFC, tonically decreasing beta-band power over parietofrontal cortex and transiently increasing gamma-band power over parietal and sensorimotor cortex through a mechanism phase locked to prefrontal theta oscillations. These findings provide clear mechanistic targets for interventional studies aimed at enhancing control over social-emotional behaviors in a number of psychopathologies.

\section{References}

Adhikari A, Topiwala MA, Gordon JA (2010) Synchronized activity between the ventral hippocampus and the medial prefrontal cortex during anxiety. Neuron 65:257-269. CrossRef Medline

Ardid S, Vinck M, Kaping D, Marquez S, Everling S, Womelsdorf T (2015) Mapping of functionally characterized cell classes onto canonical circuit operations in primate prefrontal cortex. J Neurosci 35:2975-2991. CrossRef Medline

Aron AR, Robbins TW, Poldrack RA (2014) Inhibition and the right inferior frontal cortex: one decade on. Trends Cogn Sci 18:177-185. CrossRef Medline

Aru J, Aru J, Priesemann V, Wibral M, Lana L, Pipa G, Singer W, Vicente R (2015) Untangling cross-frequency coupling in neuroscience. Curr Opin Neurobiol 31:51-61. CrossRef Medline

Badre D, D'Esposito M (2009) Is the rostro-caudal axis of the frontal lobe hierarchical? Nat Rev Neurosci 10:659-669. CrossRef Medline

Bastiaansen MC, Knösche TR (2000) Tangential derivative mapping of axial MEG applied to event-related desynchronization research. Clin Neurophysiol 111:1300-1305. CrossRef Medline 
Bastin J, Polosan M, Benis D, Goetz L, Bhattacharjee M, Piallat B, Krainik A, Bougerol T, Chabardès S, David O (2014) Inhibitory control and error monitoring by human subthalamic neurons. Transl Psychiatry 4:e439. CrossRef Medline

Boorman ED, Behrens TE, Woolrich MW, Rushworth MF (2009) How green is the grass on the other side? frontopolar cortex and the evidence in favor of alternative courses of action. Neuron 62:733-743. CrossRef Medline

Brinkman L, Stolk A, Dijkerman HC, de Lange FP, Toni I (2014) Distinct roles for alpha-and beta-band oscillations during mental simulation of goal-directed actions. J Neurosci 34:14783-14792. CrossRef Medline

Burgess PW, Dumontheil I, Gilbert SJ (2007) The gateway hypothesis of rostral prefrontal cortex (area 10) function. Trends Cogn Sci 11:290-298. CrossRef Medline

Buzsáki G, Wang XJ (2012) Mechanisms of gamma oscillations. Annu Rev Neurosci 35:203-225. CrossRef Medline

Cavanagh JF, Eisenberg I, Guitart-Masip M, Huys Q, Frank MJ (2013) Frontal theta overrides Pavlovian learning biases. J Neurosci 33:85418548. CrossRef Medline

Cavanagh JF, Figueroa CM, Cohen MX, Frank MJ (2012) Frontal theta reflects uncertainty and unexpectedness during exploration and exploitation. Cereb Cortex 22:2575-2586. CrossRef Medline

Cavanagh JF, Frank MJ (2014) Frontal theta as a mechanism for cognitive control. Trends Cogn Sci 18:414-421. CrossRef Medline

Cavanagh JF, Shackman AJ (2015) Frontal midline theta reflects anxiety and cognitive control: meta-analytic evidence. J Physiol Paris 109:3-15. CrossRef Medline

Churchland MM, Cunningham JP, Kaufman MT, Ryu SI, Shenoy KV (2010) Cortical preparatory activity: representation of movement or first cog in a dynamical machine? Neuron 68:387-400. CrossRef Medline

Cisek P, Kalaska JF (2010) Neural mechanisms for interacting with a world full of action choices. Annu Rev Neurosci 33:269-298. CrossRef Medline

Clark DM, Wells A (1995) A cognitive model of social phobia. In: Social phobia: diagnosis, assessment and treatment (Heimberg RG, Liebowitz MR, Hope DA, Schneier FR, eds), pp 69-93. New York, NY: Guilford.

Cole SR, van der Meij R, Peterson EJ, de Hemptinne C, Starr PA, Voytek B (2017) Nonsinusoidal beta oscillations reflect cortical pathophysiology in Parkinson's disease. J Neurosci 37:4830-4840. CrossRef Medline

Colgin LL (2013) Mechanisms and functions of theta rhythms. Annu Rev Neurosci 36:295-312. CrossRef Medline

Cooper PS, Wong AS, Fulham WR, Thienel R, Mansfield E, Michie PT, Karayanidis F (2015) Theta frontoparietal connectivity associated with proactive and reactive cognitive control processes. Neuroimage 108:354363. CrossRef Medline

Craske MG, Stein MB (2016) Anxiety. Lancet 388:3048-3059. CrossRef Medline

Daw ND, O’Doherty JP, Dayan P, Seymour B, Dolan RJ (2006) Cortical substrates for exploratory decisions in humans. Nature 441:876-879. CrossRef Medline

de Lange FP, Jensen O, Bauer M, Toni I (2008) Interactions between posterior gamma and frontal alpha/beta oscillations during imagined actions. Front Hum Neurosci 2:7. CrossRef Medline

Donner TH, Siegel M, Fries P, Engel AK (2009) Buildup of choicepredictive activity in human motor cortex during perceptual decision making. Curr Biol 19:1581-1585. CrossRef Medline

Enter D, Spinhoven P, Roelofs K (2016) Dare to approach: single dose testosterone administration promotes threat approach in patients with social anxiety disorder. Clin Psychol Sci 4:1073-1079. CrossRef

Etkin A, Egner T, Kalisch R (2011) Emotional processing in anterior cingulate and medial prefrontal cortex. Trends Cogn Sci 15:85-93. CrossRef Medline

Etkin A, Egner T, Peraza DM, Kandel ER, Hirsch J (2006) Resolving emotional conflict: a role for the rostral anterior cingulate cortex in modulating activity in the amygdala. Neuron 51:871-882. CrossRef Medline

Gaetz W, Liu C, Zhu H, Bloy L, Roberts TP (2013) Evidence for a motor gamma-band network governing response interference. Neuroimage 74 : 245-253. CrossRef Medline

Grent-'t-Jong T, Oostenveld R, Jensen O, Medendorp WP, Praamstra P (2013) Oscillatory dynamics of response competition in human sensorimotor cortex. Neuroimage 83:27-34. CrossRef Medline

Gross J, Kujala J, Hämäläinen M, Timmermann L, Schnitzler A, Salmelin R (2001) Dynamic imaging of coherent sources: studying neural interac- tions in the human brain. Proc Natl Acad Sci U S A 98:694-699. CrossRef Medline

Hämäläinen M, Hari R, Ilmoniemi RJ, Knuutila J, Lounasmaa OV (1993) Magnetoencephalography-theory, instrumentation, and applications to noninvasive studies of the working human brain. Rev Mod Phys 65:413. CrossRef

Hare B (2017) Survival of the friendliest: homo sapiens evolved via selection for prosociality. Annu Rev Psychol 68:155-186. CrossRef Medline

Harris AZ, Gordon JA (2015) Long-range neural synchrony in behavior. Annu Rev Neurosci 38:171-194. CrossRef Medline

Helfrich RF, Knight RT (2016) Oscillatory dynamics of prefrontal cognitive control. Trends Cogn Sci 20:916-930. CrossRef Medline

Heuer K, Rinck M, Becker ES (2007) Avoidance of emotional facial expressions in social anxiety: the approach-avoidance task. Behav Res Ther 45:2990-3001. CrossRef Medline

Jenkinson N, Brown P (2011) New insights into the relationship between dopamine, beta oscillations and motor function. Trends Neurosci 34: 611-618. CrossRef Medline

Jensen O, Mazaheri A (2010) Shaping functional architecture by oscillatory alpha activity: gating by inhibition. Front Hum Neurosci 4:186. CrossRef Medline

Jensen O, Goel P, Kopell N, Pohja M, Hari R, Ermentrout B (2005) On the human sensorimotor-cortex beta rhythm: sources and modeling. Neuroimage 26:347-355. CrossRef Medline

Jensen O, Spaak E, Park H (2016) Discriminating valid from spurious indices of phase-amplitude coupling. eNeuro 3:ENEURO.0334-16.2016. CrossRef Medline

Kalisch R (2009) The functional neuroanatomy of reappraisal: time matters. Neurosci Biobehav Rev 33:1215-1226. CrossRef Medline

Karalis N, Dejean C, Chaudun F, Khoder S, Rozeske RR, Wurtz H, Bagur S, Benchenane K, Sirota A, Courtin J, Herry C (2016) 4-hz oscillations synchronize prefrontal-amygdala circuits during fear behavior. Nat Neurosci 19:605-612. CrossRef Medline

Kaufman MT, Churchland MM, Ryu SI, Shenoy KV (2014) Cortical activity in the null space: permitting preparation without movement. Nat Neurosci 17:440-448. CrossRef Medline

Khanna P, Carmena JM (2017) Beta band oscillations in motor cortex reflect neural population signals that delay movement onset. Elife 6: pii: e24573. CrossRef Medline

Khemka S, Barnes G, Dolan RJ, Bach DR (2017) Dissecting the function of hippocampal oscillations in a human anxiety model. J Neurosci 37:68696876. CrossRef Medline

Koechlin E (2016) Prefrontal executive function and adaptive behavior in complex environments. Curr Opin Neurobiol 37:1-6. CrossRef Medline

Lisman JE, Jensen O (2013) The theta-gamma neural code. Neuron 77: 1002-1016. CrossRef Medline

Louise von Borries AK, Volman I, de Bruijn ER, Bulten BH, Verkes RJ, Roelofs K (2012) Psychopaths lack the automatic avoidance of social threat: relation to instrumental aggression. Psychiatry Res 200:761-766. CrossRef Medline

Lozano-Soldevilla D, Ter Huurne N, Oostenveld R (2016) Neuronal oscillations with non-sinusoidal morphology produce spurious phase-toamplitude coupling and directionality. Front Comput Neurosci 10:87. CrossRef Medline

Makeig S, Bell AJ, Jung T-P, Sejnowski TJ (1996) Independent component analysis of electroencephalographic data. Adv Neural Inf Process Syst 8:145-151.

Mansouri FA, Koechlin E, Rosa MGP, Buckley MJ (2017) Managing competing goals-a key role for the frontopolar cortex. Nat Rev Neurosci 18 : 645-657. CrossRef Medline

Maris E, Oostenveld R (2007) Nonparametric statistical testing of EEG-and MEG-data. J Neurosci Methods 164:177-190. CrossRef Medline

Mars RB, Jbabdi S, Sallet J, O'Reilly JX, Croxson PL, Olivier E, Noonan MP, Bergmann C, Mitchell AS, Baxter MG, Behrens TE, Johansen-Berg H, Tomassini V, Miller KL, Rushworth MF (2011) Diffusion-weighted imaging tractography-based parcellation of the human parietal cortex and comparison with human and macaque resting-state functional connectivity. J Neurosci 31:4087-4100. CrossRef Medline

Miller BT, D'Esposito M (2005) Searching for "the top" in top-down control. Neuron 48:535-538. CrossRef Medline

Morawetz C, Bode S, Derntl B, Heekeren HR (2017) The effect of strategies, goals and stimulus material on the neural mechanisms of emotion regu- 
lation: A meta-analysis of fMRI studies. Neurosci Biobehav Rev 72:111128. CrossRef Medline

Neubert FX, Mars RB, Thomas AG, Sallet J, Rushworth MF (2014) Comparison of human ventral frontal cortex areas for cognitive control and language with areas in monkey frontal cortex. Neuron 81:700-713. CrossRef Medline

Nolte G (2003) The magnetic lead field theorem in the quasi-static approximation and its use for magnetoencephalography forward calculation in realistic volume conductors. Phys Med Biol 48:3637-3652. CrossRef Medline

Oostenveld R, Fries P, Maris E, Schoffelen JM (2011) FieldTrip: open source software for advanced analysis of MEG, EEG, and invasive electrophysiological data. Comput Intell Neurosci 2011:156869. CrossRef Medline

Percival DB, Walden AT (1993) Spectral analysis for physical applications. Cambridge, UK: Cambridge University.

Phillips JM, Vinck M, Everling S, Womelsdorf T (2014) A long-range frontoparietal 5-to 10-hz network predicts "top-down" controlled guidance in a task-switch paradigm. Cereb Cortex 24:1996-2008. CrossRef Medline

Picazio S, Veniero D, Ponzo V, Caltagirone C, Gross J, Thut G, Koch G (2014) Prefrontal control over motor cortex cycles at beta frequency during movement inhibition. Curr Biol 24:2940-2945. CrossRef Medline

Radke S, Roelofs K, de Bruijn ER (2013) Acting on anger: social anxiety modulates approach-avoidance tendencies after oxytocin administration. Psychol Sci 24:1573-1578. CrossRef Medline

Radke S, Volman I, Kokal I, Roelofs K, de Bruijn ERA, Toni I (2017) Oxytocin reduces amygdala responses during threat approach. Psychoneuroendocrinology 79:160-166. CrossRef Medline

Ramnani N, Owen AM (2004) Anterior prefrontal cortex: insights into function from anatomy and neuroimaging. Nat Rev Neurosci 5:184-194. CrossRef Medline

Ridderinkhof KR, Ullsperger M, Crone EA, Nieuwenhuis S (2004) The role of the medial frontal cortex in cognitive control. Science 306:443-447. CrossRef Medline

Rowe J, Hughes L, Eckstein D, Owen AM (2008) Rule-selection and actionselection have a shared neuroanatomical basis in the human prefrontal and parietal cortex. Cereb Cortex 18:2275-2285. CrossRef Medline

Schoffelen JM, Poort J, Oostenveld R, Fries P (2011) Selective movement preparation is subserved by selective increases in corticomuscular gamma-band coherence. J Neurosci 31:6750-6758. CrossRef Medline

Spielberger CD, Gorsuch RL, Lushene RE (1970) Manual for the state-trait anxiety inventory. Palo Alto, CA: Consulting Psychologists Press.
Spinks RL, Kraskov A, Brochier T, Umilta MA, Lemon RN (2008) Selectivity for grasp in local field potential and single neuron activity recorded simultaneously from M1 and F5 in the awake macaque monkey. J Neurosci 28:10961-10971. CrossRef Medline

Stolk A, Todorovic A, Schoffelen JM, Oostenveld R (2013) Online and offline tools for head movement compensation in MEG. Neuroimage 68: 39-48. CrossRef Medline

Swann NC, Cai W, Conner CR, Pieters TA, Claffey MP, George JS, Aron AR, Tandon N (2012) Roles for the pre-supplementary motor area and the right inferior frontal gyrus in stopping action: electrophysiological responses and functional and structural connectivity. Neuroimage 59: 2860-2870. CrossRef Medline

Tyborowska A, Volman I, Smeekens S, Toni I, Roelofs K (2016) Testosterone during puberty shifts emotional control from pulvinar to anterior prefrontal cortex. J Neurosci 36:6156-6164. CrossRef Medline

van Elswijk G, Maij F, Schoffelen JM, Overeem S, Stegeman DF, Fries P (2010) Corticospinal beta-band synchronization entails rhythmic gain modulation. J Neurosci 30:4481-4488. CrossRef Medline

Volman I, Roelofs K, Koch S, Verhagen L, Toni I (2011a) Anterior prefrontal cortex inhibition impairs control over social emotional actions. Curr Biol 21:1766-1770. CrossRef Medline

Volman I, Toni I, Verhagen L, Roelofs K (2011b) Endogenous testosterone modulates prefrontal-amygdala connectivity during social emotional behavior. Cereb Cortex 21:2282-2290. CrossRef Medline

Volman I, Verhagen L, den Ouden HE, Fernández G, Rijpkema M, Franke B, Toni I, Roelofs K (2013) Reduced serotonin transporter availability decreases prefrontal control of the amygdala. J Neurosci 33:8974-8979. CrossRef Medline

Volman I, von Borries AKL, Bulten BH, Verkes RJ, Toni I, Roelofs K (2016) Testosterone modulates altered prefrontal control of emotional actions in psychopathic offenders. ENeuro 3: pii: ENEURO.0107-15.2016. CrossRef Medline

Voytek B, Kayser AS, Badre D, Fegen D, Chang EF, Crone NE, Parvizi J, Knight RT, D'Esposito M (2015) Oscillatory dynamics coordinating human frontal networks in support of goal maintenance. Nat Neurosci 18: 1318-1324. CrossRef Medline

Yamawaki N, Stanford IM, Hall SD, Woodhall GL (2008) Pharmacologically induced and stimulus evoked rhythmic neuronal oscillatory activity in the primary motor cortex in vitro. Neuroscience 151:386-395. CrossRef Medline 